\title{
Parámetros de valoración para el decomiso ambiental en los procesos
} administrativos sancionatorios

\section{Valuation parameters for environmental confiscation in sanctioning administrative processes}

\author{
Fernando Alfredo Torres-Villizhañay \\ fernando.torres@ucacue.edu.ec \\ Universidad Católica de Cuenca, Cuenca \\ Ecuador \\ https://orcid.org/0000-0001-7450-5843 \\ Juan Carlos Erazo-Álvarez \\ jcerazo@ucacue.edu.ec \\ Universidad Católica de Cuenca, Cuenca \\ Ecuador \\ https://orcid.org/0000-0001-6480-2270 \\ Diego Adrián Ormaza-Ávila \\ daormazaa@ucacue.edu.ec \\ Universidad Católica de Cuenca, Cuenca \\ Ecuador \\ https://orcid.org/0000-0002-0934-8471 \\ Cecilia Ivonne Narváez-Zurita \\ inarvaez@ucacue.edu.ec \\ Universidad Católica de Cuenca, Cuenca \\ Ecuador \\ https://orcid.org/0000-0002-7437-9880
}

Recibido: 15 de noviembre de 2019

Aprobado: 16 de diciembre de 2019 


\title{
RESUMEN
}

Se analiza el procedimiento para la aplicación del decomiso en los procesos administrativos sancionatorios ambientales, se observa como problemática que no existen parámetros para determinar el decomiso de medios de transporte en materia ambiental, sin instaurar un parámetro para realizarlo con atenuantes y agravantes, se razona que hay un conflicto de derechos, que son los derechos de la naturaleza y del trabajo. La metodología es básicamente cualitativa y su fin último es el descubrimiento de las causas, en relación con el análisis de una recopilación bibliográfica. Se plantea mediante un procedimiento con parámetros adecuados efectuar el decomiso de los medios de transporte con la aplicación de la Ley que regula las actividades ambientales, por medio de las instituciones que efectúan el control ambiental, con la aplicación de principios fundamentales, la valoración de las atenuantes y agravantes dentro del proceso administrativo que son las circunstancias que motivan el proceso.

Descriptores: Principios; derechos a la naturaleza y el trabajo; atenuantes; agravantes; proporcionalidad.

\begin{abstract}
The procedure for the application of the seizure in the administrative sanctioning environmental processes is analyzed, it is observed as problematic that there are no parameters to determine the confiscation of means of transport in environmental matters, without establishing a parameter to perform it with mitigating and aggravating factors, it is reasoned that there is a conflict of rights, which are the rights of nature and labor. The methodology is basically qualitative and its ultimate goal is the discovery of the causes, in relation to the analysis of a bibliographic compilation. It is proposed by means of a procedure with adequate parameters to carry out the confiscation of the means of transport with the application of the Law that regulates the environmental activities, through the institutions that carry out the environmental control, with the application of fundamental principles, the valuation of the mitigating and aggravating factors within the administrative process that are the circumstances that motivate the process.
\end{abstract}

Descriptors: Principles, rights to Nature and Work, mitigating, aggravating, proportionality. 


\section{INTRODUCCIÓN}

La Constitución de la República del Ecuador del 2008 (CRE), dentro de sus aspectos de importancia se instaura los derechos fundamentales, aquellos derechos que tienen la obligación de garantizar su cumplimiento y protegerlos la normativa infraconstitucional, mismos derechos que están vinculados con la dignidad humana, también son esenciales en el sistema político; haciendo alusión a esto, el tema de análisis del trabajo de investigación, nos vamos a referir a los derechos de la naturaleza reconocidos por la carta magna, que contienen un conjunto de elementos primordiales que componen la naturaleza el respeto integral de su existencia y el mantenimiento y regeneración de sus ciclos vitales, estructura, funciones y procesos evolutivos.

De la naturaleza o Pacha Mama, donde se reproduce y realiza la vida, tiene derecho a que se respete integralmente su existencia y el mantenimiento y regeneración de sus ciclos vitales, estructura, funciones y procesos evolutivos. Toda persona, comunidad, pueblo o nacionalidad podrá exigir a la autoridad pública el cumplimiento de los derechos de la naturaleza. Para aplicar e interpretar estos derechos se observarán los principios establecidos en la Constitución, en lo que proceda. El Estado incentivará a las personas naturales y jurídicas, y a los colectivos, para que protejan la naturaleza, y promoverá el respeto a todos los elementos que forman un ecosistema. (Constituyente, 2008, art.71)

En consideración también se describe otro derecho constitucional de gran importancia, que es el derecho al trabajo, el cual es un pedestal para la economía, ya que se considera como un derecho económico para beneficio de la comunidad siendo un deber de todo ciudadano ecuatoriano con la sociedad. "El Estado garantizará a las personas trabajadoras el pleno respeto a su dignidad, una vida decorosa, remuneraciones y retribuciones justas y el desempeño de un trabajo saludable y libremente escogido o aceptado" (Constituyente, 2008, art.33). El trabajo siempre a favor de llevar un crecimiento del patrimonio para un Estado garantista, quien en plena obligación, tiene el deber de cuidar que dentro de su gobierno se conciba el trabajo por medio de un procedimiento adecuado, eficaz, cumpliendo las normas fundamentales apegadas a los 
derechos humanos, manifestados en textos internacionales como los tratados, pactos internacionales de derechos Humanos y Económicos.

Con estos antecedentes se considera que hay un conflicto de derechos en la actualidad al aplicar el Código Orgánico del Ambiente (COA) y el Reglamento al Código Orgánico del Ambiente (RCOA); derechos establecidos en la CRE, que son los derechos de la naturaleza y el derecho al trabajo. Se plantea que por medio de un procedimiento con parámetros adecuados efectuar el decomiso de los medios de transporte con la aplicación de la Ley que regula las actividades ambientales, por medio de las instituciones que efectúan el control ambiental, así como la aplicación de principios fundamentales que direccionan el correcto procedimiento.

La aplicación correcta de sanciones a infractores mediante el derecho al juez natural, que es un derecho reconocido a nivel nacional e internacional así incluye un juez independiente, imparcial, predeterminado por la ley también la posibilidad de toda persona en acudir a los órganos jurisdiccionales se hace valer el derecho a la tutela judicial, a través del procedimiento adecuado utilizando las garantías mínimas, el resultado será la decisión adecuada con un resultado satisfactorio.

El decomiso de medios de transporte en materia ambiental por infringir el COA quebranta el derecho al trabajo, al no establecer la proporcionalidad de la infracción, al aplicar el decomiso de los medios de transporte sin establecer un parámetro para realizarlo con atenuantes y agravantes, se vulnera el derecho al trabajo, ya que la mayoría de vehículos que realizan transporte, tenencia, posesión de producto forestal son de ciudadanos que se encuentran ejerciendo su derecho al trabajo.

La figura del decomiso en los procesos administrativos, se rige mediante el marco legal ambiental vigente; dentro de las actividades de regulación y control de la Autoridad Ambiental; se hace efectivo el decomiso ambiental de todas las herramientas que son medios utilizados para cometer la infracción ambiental que señala la ley, ante esto se desarrolla algunas inquietudes para actuar con el decomiso, que debe realizarse sin 
vulnerar ningún derecho del infractor, lo que se ejecutará con el debido procedimiento, mecanismos técnicos jurídicos que debe cumplir al aplicar la figura del decomiso.

Se concibe por decomiso como una figura jurídica de sanción por la realización de actos contra el tenor de leyes prohibitivas o por incumplimiento de obligaciones de realizar, a cargo de los usuarios de servicios entregados por la autoridad que regula y controla, que se expone en las herramientas que fueron utilizadas dentro de la infracción que se pretende sancionar.

En nuestro caso de sustento infracciones ambientales administrativa, los que han resultado como fruto de tales ilícitos o bien los que por sus características, representan un peligro para la sociedad o perjuicio para el Estado; en nuestro tema de análisis apegado al procedimiento administrativo ambiental, como sanción se aplicará el decomiso por la infracción a la normativa ambiental vigente. En virtud a esto nos lleva a forjar como problema en la presente investigación ¿Cómo mejorar el procedimiento para la aplicación del decomiso en los procesos administrativos ambientales? De modo que el objetivo es: Proponer parámetros en el procedimiento de aplicación a la Ley Ambiental Vigente que permita su mejoramiento respecto a la falta de medidas para la atención en los procesos administrativos ambientales.

\section{DESARROLLO}

\section{Principios de aplicación en la sustanciación de procedimientos administrativos sancionatorios para la autoridad ambiental.}

En relación a los principios de atención en los procesos administrativos sancionatorios, se hace referencia a los manifestados en nuestra Carta Magna como también los que se establecen en la normativa infraconstitucional, mismos que hacen reseña de aplicación de derechos, que se tiene el deber obligatorio de su debido cumplimiento, al precautelar estos principios básicos de derechos nos proporciona una seguridad jurídica y un debido proceso eficaz. Como precepto básico (Constituyente, 2008) afirma. "Todos los principios y los derechos son inalienables, irrenunciables, indivisibles, 
interdependientes y de igual jerarquía". (art.11, n.6) En este contexto se toma la idea de una línea adecuada en la aplicación de principios constitucionales en los procesos administrativos sancionatorios, sin tener un incoveniente en caer en una vulneración al procedimiento.

Los principios de carácter infraconstitucional que se encuentran en normativas de aplicación como el COA y el Código Orgánico Administrativo (COAdministrativo) para el procedimiento sancionatorio, son indispensables, los que establecen en la normativa vigente, en el COAdministrativo tanto los principios generales y los principios de aplicación para el procedimiento administrativo, demandados en la aplicacación continua y eficaz. El principio de análisis dentro del tema investigativo con gran vinculación es el principio de responsabilidad, en primer punto quedaría claro a que se refiere el principio de responsablidad atribuido a lo referido en el COAdministrativo norma escencial de procesos sancionatorios.

El Estado responderá por los daños como consecuencia de la falta 0 deficiencia en la prestación de los servicios públicos o las acciones u omisiones de sus servidores públicos o los sujetos de derecho privado que actúan en ejercicio de una potestad pública por delegación del Estado y sus dependientes, controlados o contratistas. (Constituyente, 2017, art.15)

Este principio aplica en relación al de proporcionalidad ya que el ejercicio del funcionario público esta en la ejecución de aplicación de principios dentro de los procesos administrativos sancionaorios, la regulación hay y esta manifestada en la normtiva vigente, es una linea transversal ya demarcada que debemos darle la continua aplicación, con el apoyo de más principios, el de buena fe se refiere a un principio como uno de los principales de aplicación de derecho, es una regulación, cae en un principio de regulación, se realiza el análisis desde un punto iusfilosófica, se percibirán como un principio de regulación concreta, básica y firme, con dificultad de enfatizar con demás principios pero es esencial al enmarcar en una postura ideal.

En relación a a este principio es importante por lo tanto destacar que la aplicación del principio no esta limitada a las actuaciones en la que se produce un ejercicio de 
derechos. Como tales, los principios generales de derecho no tienen la estructura lógica de las típicas normas jurídicas, es decir carecen de un supuesto de hecho suficientemente precisado y una consecuencia jurídica con similar propósito de precisión. Juan Pablo Cajarville expresa que los principios no definen, o lo hacen muy genéricamente, una hipótesis de hecho o supuesto normativo, limitándose muchas veces a afirmar valores o jerarquizaciones de valores de origen "metajurídico" que a través del principio adquieren relevancia jurídica. Agrega que aun cuando pueda extraerse de ellos la identificación de un supuesto jurídico, no surgirá del principio la imputación a ese supuesto de una consecuencia jurídica determinada (Goñi, 2016).

De este modo se analiza los principios con relación con las personas los cuales en común con el COA, son el principio de arbitrariedad que desde la perpectiva se considera que, si bien la interdicción de la arbitrariedad tiene su raíz en la iguadad plasmada dentro de la legislación aplicable mediante la función del Estado que se ocupa en generarla, dentro de la arbitrariedad hay ogunos puntos de proyección que engloba la arbitrariedad, hay etapas de subjetividad, como una concepción aludida a este principio se puede notar como justicia de desigualdad, de abuso de poder por algún factor que el funcionario encargado de aplicarlo, aquí cabe el test de aplicación directa de la razonabilidad y roporcionalidad en común con la actuación de la arbitrariedad (Rojas, 2017).

Lo cual dará este principio como una independencia de los servidores públicos que evitará el resolver los procesos sancionatorios administrativos por motivos de no pertenencia al asunto en discusión sobre conflictos de no interés dentro del centro de interés o discordantes al tema de interes usual, con un examen total en la materia y no dejarse llevar por asuntos indirectos. Tambíen en virtud a seguir con el análisis de los principios de la actividad administrativa con relación con las personas, se valora al principio de control, que se refiere al control de actividades que administra los entes de administración pública sobre su potenstad sancionatoria, sin implicar una afectación en ejercicio de sus competencias asignadas y adquiridad como órganos reguladores y de 
control de actividades, aplicando los mecanismos previstos tanto en la Carta Magna CRE como en las normas infraconstitucionales en este caso COA y RCOA.

Asi se relaciona con el principio de la ética e integridad pública, aplicable a los funcionarios públicos con los servicios de honestidad, lealtad y rectitud, que de acuerdo al desempeño de sus funciones laborales deben contener una serie de valores, que son un conglomerado que hace ejercicio correcto al bien común aplicable de la normativa vigente, su transparencia, eficiencia, dedicacíon del desempeño en su trabajo con los altos parámetros profesionales, con un interés general y común para el beneficio de la colectividad sobre un particular, que se discute sobre si es fondo de sanción o no. En este orden de ideas Comadira (2003) asevera: "El principio de ética es la veracidad, transparencia, fundamentación y evaluación; ejercicio adecuado del cargo; uso adecuado de los bienes; uso adecuado del tiempo; régimen de declaraciones juradas; Régimen de beneficios y regalos" (p.145). Al indicar que en el principio de la ética pública va de la mano del desempeño de los funcionarios públicos dentro de sus labores, se deja claro que no hay una moral diferenciada, pública y prinvada sino son conjuntas iguales en sus factores.

Siguiendo con la sustentación de este tema se va a referir sobre la seguridad jurídica y la confianza legítima un principio de suma importancia para los procesos administrrativos. Todas las administraciones su ejecución de funciones se generan por los requisitos de certeza y privacidad, estas guardan un respeto de lo generado en el pasado, se toma en consideración la aplicabilidad dela confianza legítima que manifiesta nuestra carta magna "La aplicación del principio de confianza legítima, se deja claro que los errores de acción y omisión de los funcionarios públicos no deben afectar en las decisiones de una resolución".

En resumen la seguridad jurídica es reconocer cuales son las consecuencias jurídicas ante actos que son propios, individual como respuesta al ordenamiento legal que se contraería, en caso de no actuar en sujeción o apegado al marco legal. En la Carta Magna también se refiere a la seguridad jurídica, como principio prioritario, (Gracia 
Panta, Rodríguez Mera \& Gracia Panta, 2019), por cuanto este se vincula con todos los poderes públicos como también el sistema judicial, no a una intermediación entre los enunciados constitucionales y su aplicación, en breves rasgos directa e inmediata. Queda claro la seguridad jurídica dentro de su avaluo es principio no como un valor, en las normativas vigentes, que es escencial porque se ve como una guente de derecho que nos ayuda en la falta de ley.

La seguridad jurídica sería así el resultado de un conjunto de técnicas normativas encaminadas a garantizarla propia consistencia del sistema. Dentro de las leyes si hay una contradicción no deben ser aplicables. Por tanto, principios como los de jerarquía normativa, irretroactividad, o técnicas como las de derogación implícita, o analogía, vienen a conseguir la seguridad como valor específicamente jurídico: es decir, la seguridad jurídica es un valor necesario para la realización de los valores que el ordenamiento jurídico pretenda realizar sean en mayor o menor grado igualdad, libertad, felicidad, etc.), y en este sentido es un valor adjetivo de aquéllos. (Sánchez-Pesacador, 1989, p.198 - 199)

Respecto al principio de racionalidad se hace énfasis a las decisiones de autoridades administradores de justicia enmarcado a sus competencias tanto judiciales como administrativa deben realizar mediante una resolución o sentencia motivada, con aspectos técnicos jurídicos valederos de descarga en la actuación del proceso, que se evidencia fundamentos de hecho y derecho bien configurados y relacionados con la actividad realizada por el administrado para efectuar plena validez en su desiciónm sin caer en vulneración de derechos, hay una obligación de motivar las sanciones administrativas, es una decisión más allá de ocupar todos los espacios, sería de llegar más alla de una calificación de la aplicaciín normativa vigente, como fundamentos de derecho relacionados en conjunto con los fundamentos de hechos, concretamente las circunstancias suscitadas, una parte mas amplia, de una acción que encaje con la conducta en contra de la normativa tipificada en la ley específica de sanción, asi moderando también la aplicación y relación de conceptos que van en correlación a la conducta penada. 
En esa tarea de especificar la selección o de determinación de los criterios que sirven para tomar decisiones en los espacios correspondientes a los márgenes de una apreciación y esa tarea de examinar la justificación de los criterios adoptados, sería también fundamental en la motivación de las decisiones administrativas (Pontón, 2011). A tomar en cuenta sobre el principio de racionalidad como toda obra de la motivación, asi también en protección de los derechos establecidos en la CRE sin dejar de lado lo establecido (Asamblea Constituyente, 2008) afirma:

Las resoluciones de los poderes públicos deberán ser motivadas. No habrá motivación si en la resolución no se enuncian las normas o principios jurídicos en que se funda y no se explica la pertinencia de su aplicación a los antecedentes de hecho. Los actos administrativos, resoluciones o fallos que no se encuentren debidamente motivados se considerarán nulos. Las servidoras o servidores responsables serán sancionados. (art.76, I.L)

En virtud a que todo proceso se incluya las garantías básicas que se encargará el debido proceso en velar sobre el cumplimiento en analogía a los deberes y derechos adquiridos, en atencedente a estos es uno de los más importantes principios de aplicación a los procesos administrativos sancionatorios; terminando con los principios de la actividad administrativa en correspondencia con las personas, se analiza el principio de protección a la intimidad personal de datos personales, garantizando a la privacidad y el manejo adecuado de estos datos que se ven vinculados con la vida privada de los administrados, con la suma protección y adecuada manipulación de estos mencionados datos sin causar perjuicio al trasgresor de la normativa ambiental vigente.

Al fijar que en la actualidad los operadores de adminstración de sanciones administrativas, funcionares que por la era digital, los datos personales de los administrados son manejados por plataformas digitales que son herramientas proporcionadas por la misma administración pública con el fin de agilitar los trámites, lo que compromete a un manejo adecuado por el funcionario público sin violentar el derecho a la intimidad de datos personales, (Asensio, 2005) abarca como idea de los 
problemas que se generan con la evolución de la tecnología dentro de nuestra legislación como administración de justicia.

Cabría tener claro sobre lo principal partir del tratamiento de los problemas informáticos en la administración de justicia, casos judiciales y administrativos sancionatorios teniendo en cuenta sobre el la obligación de la utilización de las tecnologías que se mencionan en la normativa ocupando un espacio. Tema para referirse que sería de compleja actuación en sobre su implantación de la tecnología dentro de los procesos que llevan los operadores de justicia ya que la nfoación que se maneja es personal y su divulgación puede vulnerar la intimidad personal.

Se continua con la aplicabilidad de los principios de relaciones entre administraciones públicas ahora en mención a la lealtad institucional, no es más que el respeto de las competencias entre instituciones públicas, con la colaboraciones entre si, como ejemplo el intercambio de información que pueda servir en beneficio de la eficiencia, valores que intervienen en la conducta del funcionario o empleado público obligado a tenerlos en cuenta en sus competencias (Garcia, 2000). Hay otro principio que marca sobre una buena aplicación que es el de corresponsabilidad y complementaridad, sencillo de responsabilidad compartida que debe ser repartida en función a sus competencias, con resultados en unión institucional para completar objetivos de una armonia de Estado y efectivo goce de ejercicos de derechos, como por ejemplo cuando una institución tiene la accción de control en actividades de recursos naturales especificos y otra institución tiene adquirido competencias de una parte de estos recursos naturales, lo que traerá a determinar afección por actividades a cada recurso natural y responder el administrado a cada institución, también con el intercambio de cumplimiento de actividades como informes de inspecciones a realizar, para que cada quien actue debidamente, asi adquiere responsabilidad y a su vez la entregan.

El principio de subsidiariedad, como fin alcanzar el objetivo, meta que otra institución no logra alcanzar, como inferior o menor rango, de jerarquia mínima, esta puede ser por la jurisdicción abarcará funciones para solventar el requerimiento necesario a completar 0 
continuar con el trámite alcanzado. Pasando al último principio de las relaciones entre las administraciones públicas se indica sobre el de colaboración que funcionaría como mecanismo de colaboración y coordinación entre entes públicos con el fin de ocupar todas las competencias y el menor gasto de recursos, esta colaboración es voluntaria pero siempre a favor de velar por el cumplimiento de sus funciones a la necesidad de actuar si lo demanda la actividad, es en resumen una colaboración armónica como se vayan interactuando los poderes públicos, con la armonía de la relación de cada uno de ellos como objetivo llegar al propósito del Estado.

También se vicula al poder político por cuanto al hablar de este, por medio de un gobierno ejerce total poder sobre un Estado, que con sus entes se encuentran obligadas a colaborar y cooperar por una voluntal estatal, un suave fluir, donde termina la colaboración es en inervenir en las actividades de otro ente estatal ya que si hubiera intervención rompería con la separación total de poderes. En el caso de la regulación de los principios que establece la ley en el procedimiento administrativoambiental sancionador un principal el de tipicidad, no más que sanciones contempladas en la ley, que una infracción cometida tiene que establecer una sanción, tiene que encontrarse referida en la ley especificamente, no da paso a la interpretación o una similar, en el derecho administrativo sancionador es un principio sustantivo para el administrado, se da una debida aplicación de sanciones con este principio cuando se comete una infracción administrativa.

Referirse a la tipicidad en el derecho administrativo sancionador es evocar la precisión del régimen sancionador, en el tanto lo que se resuelva es de conformidad con la legalidad del ordenamiento jurídico, sin que exista una banda amplia de sanciones, que genere incertidumbre e ilegalidad, generada por esa falta de precisión y, que repercute en lesión del debido proceso. La tipicidad es necesariamente precisión, en favor de la legalidad y de las garantías del debido proceso, para que los procedimientos administrativos sancionadores se resuelvan de conformidad con el derecho, por la 
proporcionalidad y la razonabilidad de las sanciones administrativas. (Mata, 2014, p.127)

Como último principio que traza una guía para la aplicación correcta de las sanciones la tipificadad como infracción en la normativa ambiental vigente es el de irretroactividad, se refiere a la aplicación de normas vigentes detallando la infracción que puede ser adaptable al cometimiento de la infracción. "Las disposiciones sancionadoras producen efecto retroactivo en cuanto favorezcan al presunto infractor". (Asamblea Constituyente, 2017, art. 30) Con este antecedente tambien la aplicabilidad cabe sobre lo que nos dice la Carta Magna en caso mas típicos de la aplicación de la normativa es de conflicto de leyes que tienen analogía a la misma materia y que contemple sobre el mismo referido hecho o circunstancia, con la tipificación de diferente sanción, ante este hecho la aplicación será la menos rigurosa, aún cuando su promulgación sea posterior a la infracción, en el caso de duda sobre una norma que contenga sanciones, se la aplicará en el sentido más favorable a la persona infractora.

Con este sustento se opera sobre unos principios fundamentales de aplicación directa al tema de sustento directo hacia el procedimiento dentro de los procesos sancionatorios en materia ambiental. Queda claro que son lineas que nos trazan un camino resto hacia una aplicación correcta sin dar paso a una interpretación, arbitrariedad y demas preceptos que no refieran a las circunstancias de hechos y de derecho analizados y sustentados dentro del procedimiento.

Un principal el de proporcionalidad que mas adelante se explica sobre la valoración de la prueba sustentada en el proceso administrativo que son las atenuantes como circunstancias que benefician al administrado, asi también las agravantes que complican al administrado por una conducta y circunstancias negativas, estas se atrubuyen a modificar la sanción con la aplicabildad a una reducción o aumento de esta. 


\section{Valoración de atenuantes y agravantes con el principio de proporcionalidad dentro de los procesos administrativos sancionatorios.}

El COA dentro de la aplicación de principios esta la proporcionalidad de la sanción administrativa que no es mas que la imposición de una sanción a la infracción ambiental que tiene una relación entre ellas, tomando en cuenta la magnitud de la infracción, y de más consideraciones como las agravantes y atenuantes encontradas en el proceso adminstrativo y la capacidad económica que posee el infractor de acuerdo a la base imponible (Asamblea Constituyente, 2017). Referente aquello tambien se hace mención a lo sobredicho en otras normativas que el común análisis a este principio de proporcionalidad ya que se menciona en otros tienen límites para su aplicación, el mencionado principio se vuelve relevante si acepta que no existen derechos incondicionales, hay la gran posibilidad de limitar cada derecho.

La discusión es la manera para aclarar y cuales son los requisitos a cumplir (Carbonell, 2008). Asi se demuestra que este principio tiene límites pero es de gran importancia ya que la normativa que valora los procesos administrativos sancionatorios se encuentra establecido en el. Dentro de esta perspectiva Constituyente (2008) afirma: "La ley establecerá la debida proporcionalidad entre las infracciones" (art.76, n.6). Lo que es correcto se encuentra amparado en nuestra Carta Magna, que todo proceso debe estar establecido la proporcionalidad en el caso es sobre procesos administrativos sancionatorios, que cabe como una comparación de este principio un parámetro que debe cumplirse en la valoración como establece el COA seria de las atenuantes y agravantes, estas son circunstancias que estan ligadas a los hechos que dieron raiz a la infracción mismas que después seran analizadas y colocadas en un juicio para su valoración circunstancial que determinará el grado de la infracción.

La proporcionalidad responde a la razonabilidad de las sanciones, en otras palabras, podemos argumentar, que existe una razón justificadora de cada sanción normada y que es proporcional a la falta cometida. Con el debido análisis de todos los parámetros que se evaluaron al cometer esta acción que es en contra de la normativa vigente. En 
ese mismo contexto es una razonabilidad de la sanción es de carácter general de aplicación en materia que corresponda en nuestro caso administrativa, como la consecuencia de una relación necesaria a la actuación de la conducta típica la gravedad de cometida el objeto de la tutela y la consecuencia jurídica un acto carente de razonabilidad es contrario al derecho y a la justicia. Una sanción es proporcional en el tanto sea razonable para la falta cometida.

Los principios de proporcionalidad y razonabilidad justifican la predeterminación normativa, que otorga certeza jurídica al régimen sancionador, pero que a la vez justifica la seguridad jurídica de dicho régimen en relación con las garantías del administrado sobre las consecuencias de los actos y conductas que se consideran como faltas administrativas. (Mata, 2014, p.132)

Ante este principio se analiza la valoración de las agravantes y atenuantes dentro del proceso administrativo sancionatorio, en relación a la multa que se impondrá al infractor debe ser de acuerdo a la gravedad de la infracción que se categoriza de acuerdo a las mutas leves, graves y muy graves, con una proporción a la capacidad económica del infractor, aquí en este punto ya se establece como punto continuo al principio de proporcionalidad será las atenuantes y agravantes, como se expresó son circunstancias que tienen correlación con los hechos. "La multa se ponderará en función de la capacidad económica de las personas naturales o jurídicas, la gravedad de la infracción según su afectación al ambiente y considerando las circunstancias atenuantes y agravantes" (Asamblea Constituyente, 2017, art.322).

Otro asunto es de los valores para la aplicación a la multa, que será el total de la valoración de la carga de la prueba se hace en correlación a la aplicación del COA, que menciona dentro del cálculo de la multa pecuniaria de la sanción se establece de acuerdo a la valoración de la prueba mediante las agravantes y atenuantes en su valoración con la palicación de los parámetros de los principios para los procedimientos sancionatorios en principal el de proporcionalidad se verifica la existencia de circunstancias atenuantes, y en medida a reducir la multa de la mitad a la establecida 
en la ley aplicable un porcentaje considerable que favorece al administrado, pero tambíen se subirá el valor de mayor que es un cincuenta por ciento si las agravantes pasan dentro del proceso adminstrativo sancionador (Asamblea Constituyente, 2017).

La autoridad administrativa sancionadora observará la siguiente secuencia al momento de calcular las multas correspondientes a las infracciones ambientales: a) Revisará la información sobre los ingresos brutos anuales del infractor proporcionada por el SRI, para determinar su capacidad económica y a cuál de los grupos establecidos en el Código Orgánico del Ambiente pertenece; b) Determinará la base de la multa según el tipo de infracción; y, c) A la base de la multa se le aumentará o disminuirá un $50 \%$, en caso de que se verifique la existencia de agravantes o atenuantes, respectivamente. El resultado de esta última operación constituirá el valor final de la multa. (Asamblea Constituyente, 2019, art.840)

En materia ambiental se explicará las atenuantes valoradas que según el COA se refieren algunas que se encuentran normadas, en primer lugar ejecutar se encuentra realzar todo tipo de actividad que ayude a la ejecución de medidas contingentes que realizan que la actividad sea amigable con el ambiente y si generó ua afectación aplicar la remediación por medio de programas que regula la autoridad ambiental; como segundo el deber de que la autoridad ambiental se entrere mediate denuncia ciudadana obligatoriedad de informar cualquier tipo de afección ambiental; en tercero la colaboración con el ente rector y regulador; en cuarto no tener un antecedente de infractor a la normativa ambiental vigente; $\mathrm{y}$, por último los especímenes vivos entregarlos a la autoridad reguladora (Asamblea Constituyente, 2017).

Entran en la correcta aplicación a cada una de ellas, que esten referente a la circunstancia, los hecho recaigan en el cumplimiento de estas circunstancias para establecer la multa de la sanción. Así como hay las circunstancias que favorecen al administrado tambien encontramos las que no favorecen establecidad en el COA y de directa aplicación como son En el caso de reincidencia del administrado, con las infracciones ambientales que debe darse con las mismas circunstancias de la infracción de la misma naturaleza; otra es perpetrar la infracción para ocultar otra, tener el ánimo de realizar esta acción; asi también es rehuir la responsabilidad o atribuirla a terceros, 
haber cometido dicha infracción y no aceptar la responsabilidad; del modo tambien en la infracción con una conducta repetitiva, aquí esta una conducta deshonrosa que puede ser calificada con grave o muy grave; y, como sacar un fin económico para sí mismo o un tercero, esta actividad generada ha sabiendas que es una infracción lo realiza por lucrar, sacar una tajada (Asamblea Constituyente, 2017).

\section{Conflicto de derechos, la naturaleza y el trabajo.}

En materia ambiental dentro de los procesos administrativos sancionatorios, estos se fundan en la normativa ambiental vigente, dentro de la cual se entrega las competencias a la autoridad ambiental tanto en control y regulación mediante normas e instrumentos de gestión de las actividades que intervienen con el medio ambiente,las personas y diferentes nacionalidades, como comunidades. Este ejercicio de competencias ambientales Asamblea Constituyente, (2017) afirma: "comprende las facultades de rectoría, planificación, regulación, control y gestión referidas al patrimonio natural, la biodiversidad, calidad ambiental, cambio climático, zona marino y marino costera, y demás ámbitos relacionados de conformidad con la Constitución y la ley" (art.14).

En tenor a esto ahora lo determinado en el CRE sobre los derechos eatablecidos en la Carta Magna, se reconoce el derecho de la población a vivir en un ambiente sano y ecológicamente equilibrado, que garantice la sostenibilidad y el buen vivir, sumak kawsay, por lo tanto el Estado se encuentra en la obligación de hallar el equilibrio entre el dearrollo económico y la protección ambiental, determinando cuales son los riesgos permitidos y sancionando la comisión de riesgos no permitidos. Para conseguir estos hechos, en el derecho ambiental intercede en tres puntos de interés y fundamentales: primero de acuerdo a sus competencias establecidas en la CRE y normas legales es la de control ambiental, otra es de la intervención sancionatoria mediante procesos administrativos y una tercera línea de intervención encaminada a obtener la reparación de los daños causados al ambiente (Pardo, 2014). 
Nuestra Carta Magna tambien nos garantiza derechos, que obliga a los demás a cuidar la naturaleza para consumar estos derechos, todos tenemos el derecho de un ambiente sano, para conseguirlo hay una serie de factores a cumplir, que inervienen en lo principal no afectar el ambiente, otro punto que sea ecologicamente equilibrado, que todos sus recursos naturales asi como la flora y fauna, esten en los entornos adecuados, haya una fraternidad de la naturaleza con la actividad humana, que debe encontrarse con armonía con el entorno como la naturaleza. "Se habla de la vida en torno a todos sus ámbitos, es su concepción y organización lo determinante en esta racionalidad emancipadora, que acude a la integralidad del ser humano para convivir con la naturaleza en unidad" (Gómez, León, 2016, p.241).

Asi tambien se analiza el derecho al trabajo, nuesta CRE del 2008 es garante del trabajo, que sea digno, que se pueda escoger de forma libre, que los trabajadores tengan un pago económico justo y digno. "El trabajo es un derecho y un deber social, y un derecho económico, fuente de realización personal y base de la economía" (Asamblea Constituyente, 2008, art.33). También se establece en la CRE como derecho y el Estado se ve en la obligación de garantizar, tomando en cuenta sus aptitudes, conocimientos, limitaciones, para hacer efectivo su remuneración, ahora ante esto las sanciones adminstrativas ambientales se encuentran en el conflicto de al momento de hacer uso, efectivo imponer la sanción por el cometimiento de una infracción a la normativa ambiental vigente en este caso el COA, hay la discusión de la aplicación a favor de los derechos de la naturaleza transgrediendo el derecho al trabajo, con la necesidad de crear parámetros para la aplicabilidad de la sanción en especial lo que manifista la normativa sobre el decomiso de medios de transporte por la posesión, trasporte, tenencia de productos forestales.

Como se menciona a lo largo de esta investigación se tiene que precisar los parámetros de aplicabilidad para los procesos administrativos sancionatorios en materia ambiental, que caminan con los principios de aplicación en la sustanciación de procedimientos administrativos sancionatorios para la autoridad ambiental, en consideración la 
proporcionalidad que valora las circunstancias que emanan como efecto las atenuantes y agravantes, para la conclusión de esta tarea es necesario que cada principio que ya fue tema de análisis se perciba reflejado en el parámetro que valorará la prueba dentro del proceso administrativo, sin dejar de lado los derechos en discusión los de la naturaleza y del trabajo, en especial este último para no perpetrar una vulneración, derecho muy importante. "El trabajo es un derecho y un deber social" (Asamblea Constituyente, 2005, art.2).

A continuación, se presenta la Figura 1, en la cual constan los parámetros que se debería considerar al momento de la valoración de las circunstancias relacionadas con atenuantes y agravantes que determinan el proceso administrativo sancionador ambiental.

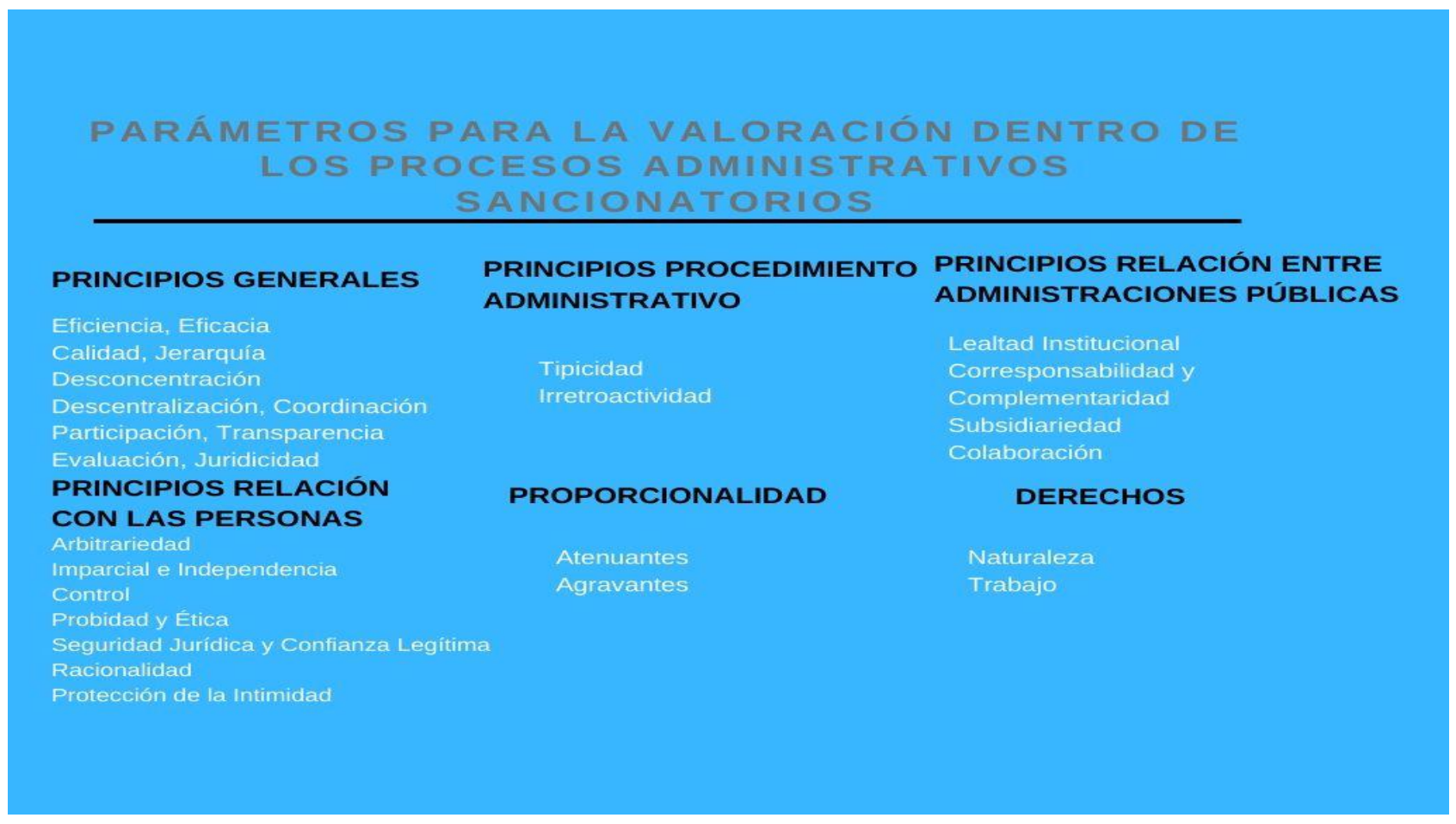

Figura 1. Parámetros para la valoración dentro de los procesos administrativos sancionatorios 


\section{METODOLOGÍA}

En virtud a la metodología que se utilizó en la actual indagación se encuentra generada en un análisis específico, generado de unos exhaustivos estudios y recolección de información bibliográfica en función del problema trazado. Como métodos aplicados son los utilzados el sintetico y el analítico, como objeto de lo principal de la investigación (Valdez, Narváez, Trelles y Erazo, 2020). En virtud ha encontrar el porque de las causas de problema lanteado que es la vulneración de derechos constitucionales, mediante algunas variables, que fue oportunamente tratadas desmenuzando el material recopilado (Rivero, 2008). En referencia a la aplicación de estos métodos, se examinó la Constitución de la República del Ecuador, Codificación de legislación ecuatoriana, Reglamentos de aplicación a los Códigos Ecuatorianos, la normativa ambiental vigente, que fue analisados con el fin de alcanzar a generar contribuciones aplicables para el procedimiento administrativo sancionatorias a la normativa ambiental vigente (Bravo, Narváez, Vázquez y Erazo, 2020).

\section{APORTES GENERADOS}

Con todos los antecedentes que se analizó en relación a dar un parámetro de valoración se despende las siguientes conclusiones:

En concluyente se debe razonar, que mediante el proceso adminstrativo sancionatorio en materia ambiental al llevar una aplicación de las sanciónes por la infracción al COA se considera que hay un conflicto de derechos constitucionales, para la correcta aplicación de las sanciones establecidas en el COA es el decomiso de medios de transporte, lo cual trasgrede directamente el derecho al trabajo y se deja de lado el derecho a la naturaleza si no se aplica lo que manifiesta el COA.

En la Carta Magna establece que los derechos constitucionales tiene que garantizarse tanto su protección y cumplimiento por medio del Estado, garantizarse una armonia entre estos dos derechos, respetando la exixtencias, mantenimiento y regeneración, de toda la actividad de la naturaleza, todos nos vemos en la obligación de cumplir en velar 
estos derechos que tiene la naturaleza, lo que hay que llevar una armonía entre el ser humano y la naturaleza, nuestra CRE tambien garantiza el derecho al trabajo, que debe velar el Estado sobre el cumplimiento de caracteristicas que debe conllevar el trabajo, que sea digno, una remuneración justa, un adecuado desempeño, libre no obligado en su elección, que no afecte a su salud, que no se perjudique el esfuerzo ejecutado para obtener una gratificación económica, todo esto es la motivación a dejar claro los parámetros que deben considerarse a la aplicabilidad de las sanciones por infracción a la normativa ambiental vigente en un proceso administrativo sancionatorio.

Conlleva a establecer como primer parámetro la aplicación de principios, mismos que son clasificados, ya que el aporte de cada uno de ellos nos fija una visión correcta de aplicación, sin vulnerar derechos, se desmenuzó de acuerdo a la aplicabilidad de cada uno de ellos, como pirmera fase estan los principios generales, que se encuentran tanto en instrumentos internacionales y normativa nacional, a continuación los de relación de la la adminstración pública con las personas que ejercen el servicio público, en seguida los que regulan las relaciones entre las instituciones públicas y por último los que se basan en el procedimiento administrativo. En común con la valoración de las circunstancias a los hechos relacionados como son las atenuantes y agravantes dentro del proceso administrativo sancionatorio, para la fijación de algunos parámetros como la multa pecuniaria, todas estas pruebas recopiladas dentro del proceso administrativo sancionatorio valorado mediante la proporcionalidad, principio que nos ayudará a generar una ponderación de los hechos ocurridos y que estan en discusión sobre si deben ser sancionados y de que manera. Se concluye generando los parámetros de aplicación al procedimiento sancionatorio en los procesos administrativos en materia ambiental sin transgredir derechos. 


\section{REFERENCIAS CONSULTADAS}

1. Asamblea Constituyente. (2005). Código del Trabajo. Quito, Pichincha, Ecuador: Registro Oficial 167.

2. Asamblea Constituyente. (2008). Constitución de la República del Ecuador . Derechos de la Naturaleza. Montecristi, Manabí, Ecuador: Registro Oficial 449.

3. Asamblea Constituyente. (2017). Código Orgánico Administrativo. Quito, Pichincha, Ecuador : 31.

4. Asamblea Constituyente. (2017). Código Orgánico del Ambiente. Quito, Pichincha, Ecuador: Registro Oficial 983.

5. Asamblea Constituyente. (2019). Reglamento al Código Orgánico del Ambiente . Quito, Pichincha, Ecuador: Registro Oficial 507.

6. Asensio, R. J. (2005). Administración de Justicia y nuevas tecnologías. Administraciones Públicas, 63-80.

7. Bravo Núñez, A. d., Narváez Zurita, C. I., Vázquez Calle, J. L., \& Erazo Álvarez, J. C. (2020). Reparación integral de la Corte Interamericana de Derechos Humanos: Sentencias de acción extraordinaria de protección. Iustitia Socialis, 600 .

8. Carbonell, M. (2008). El Principio de Proporcionalidad y la Interpretación Constitucional . Quito: Ministerio de Justicia y Derechos Humanos.

9. Comadira, J. R. (2003). Apuntes sobre los principios de ética pública en el Derecho argentino. Documentación Administrativa, 135-150.

10. Garcia, G. B. (2000). Principios de relación entre administraciones públicas. Anuario de facultade de Dereito de Universidade de Coruña, 67-82.

11. Goñi, M. L. (2016). El principio de buena fe como rector del ejercicio de la función pública. Revista de Derecho Público, 55-72.

12. Gracia Panta, E., Rodríguez Mera, L., \& Gracia Panta, K. (2019). El derecho público como regulador de las relaciones entre las personas. IUSTITIA SOCIALIS, 4(7), 146-155. doi:http://dx.doi.org/10.35381/racji.v4i7.368

13. Mata, C. A. (2014). El Principio de Tipicidad en el Derecho Administrativo Sancionador. El Foro, 121-135.

14. Pardo, J. E. (2014). Derecho del medio ambiente. Madrid: Ediciones Jurídicas y Sociales. 
15. Pontón, F. J. (2011). El principio de objetividad en el ejercicio de la potestad administrativa sancionatoria. Documentación Administrativa, 211-231.

16. Rivero, D. S. (2008). Metodología de la Investigación . Sanabria: Shalom.

17. Rojas, L. M. (2017). El Principio Constitucional de Interdicción de la arbitrariedad. Pensamiento Actual, 116-131.

18. Sánchez-Pesacador, L. L. (1989). Seguridad Jurídica y Actuación Administrativa. Documentación Administrativa, 197-210.

19. Untiveros, L. d. (2016). De los Derechos Ambientales a los Derechos de la Naturaleza. Misión Jurídica, 233-260.

20. Valdez Masache, J. A., Narváez Zurita, C. I., Trelles Vicuña, D. F., \& Erazo Álvarez, J. C. (2020). La vulneración de derechos del presunto agresor en la violencia intrafamiliar. Iustitia Socialis, 458. 